\title{
Assessment of Relationship Between Static and Dynamic Load Using Regression Analysis and Artificial Neural Network Model
}

\author{
Ahmed H. Abulkareem ${ }^{(\bowtie)}$ \\ Civil Engineering Department, Engineering College, \\ University of Anbar, Ramadi, Iraq \\ ahm1973ed@gmail.com
}

\begin{abstract}
The Light Falling Weight Deflectometer (LFWD) load test has been developed to directly estimate the in-situ elastic modulus of near surface profiles as foundation, and subgrade layers is presented in this paper. For this purpose, field tests were conducted on selected sections from landfill project within Anbar province. In addition, forty test sections were constructed and tested at the Civil Engineering Department- University of Anbar. All sections were tested using the ZFG 3000 model - LFWD in companion with the Plate Load Test (PLT) that were used as reference measurements. Regression analyses were conducted to determine the best correlations between the elastic modulus obtained from LFWD and PLT tests., $\mathrm{E}_{\mathrm{vd}}$. ANN model is used to calculate dynamic deformation modulus, $\mathrm{E}_{\mathrm{vd}}$ and comparing with the regression statistical model. The results indicate that ANN model have the capability of predicting dynamic deformation modulus, $\mathrm{E}_{\mathrm{vd}}$ with a high degree of accuracy. Good correlations were obtained, which demonstrated that the LFWD can be reliably used to predict the modules obtained from plate load test and degree of compaction values, and hence can be used to evaluate the stiffness/strength parameters of shallow subgrade layers.
\end{abstract}

Keywords: Plate load test $\cdot$ LFWD $\cdot$ Dynamic modulus $\cdot$ ANN $\cdot$ Regression analysis

\section{Introduction}

The light falling weight Deflectometer (LFWD) is used in landfill project in Iraq. The German device (ZFG 3000) from Zorn is a compaction control device used in this research. It is able to measure the dynamic load bearing capacity of subgrades, subsoils, embankment layers and backfills.

Extensive application of these apparatus still has not been achieved since the dynamic modulus in not accepted in the quality assessment and quality control process of embankments and subgrade layers. Only marginal use of these devices can be noticed, mainly on areas of low importance (e.g. road shoulders) or trenches where performing a static plate load test could be complicated (Zoltán 2008). 
For being able to use these dynamic devices on subgrade and embankment layers for landfill project, the research for converting the measured dynamic modulus into static modulus has been initiated.

The main objective was to determine the correlation between static and dynamic modules. Since direct conversion formulas are not frequently used in practice, introduction of an easy to use table with the required static and dynamic target values has been aimed. This is achieved by conducting field tests on constructed layers using the investigated device LFWD along with standard in-situ test device Plate Load Test (PLT). Otherwise new quality assessment based on dynamic modulus might be able to substitute the exclusive usage of the slow and complicated static plate load test in the near future. With the help of these results, new dynamic design methods can be worked out and applied.

\section{Light Falling Weight Deflectometer (LFWD)}

Light Falling Weight Deflectometer (LFWD) is a portable falling weight deflectometer that has been developed in Germany as an alternative in-situ testing device to the plate load test. Different types of LFWD exist in the market. All types exhibit many similarities in their mechanics of operation although there are many differences in design and mode of operation, which lead to variations in the measured results. Generally, the LFWD consist of a loading device that produces a defined load pulse, a loading plate, and one center geophone sensor (electric deflection data device) to measure the center surface deflection (Garcia and Thompson 2004).

The ZFG 3000 LFWD from Zorn Instruments was used in this study Fig. 1 is a compaction control device, according to ASTM E2835-11 and ASTM E2583-07 (2011). Dynamic modulus of deformation, $\mathrm{E}_{\mathrm{vd}}$ is the most accurate and independent means for judging deformation (stiffness) and, thus, a material's level of compaction (www.ticservicegroup.com.au, 2013).

A $10 \mathrm{~kg}$ falling weight is dropped onto a $300 \mathrm{~mm}$ diameter plate from a height of $72 \mathrm{~cm}$ through guide rod; the vertical displacement of the plate $\left(\delta_{c}\right)$ is recorded by an

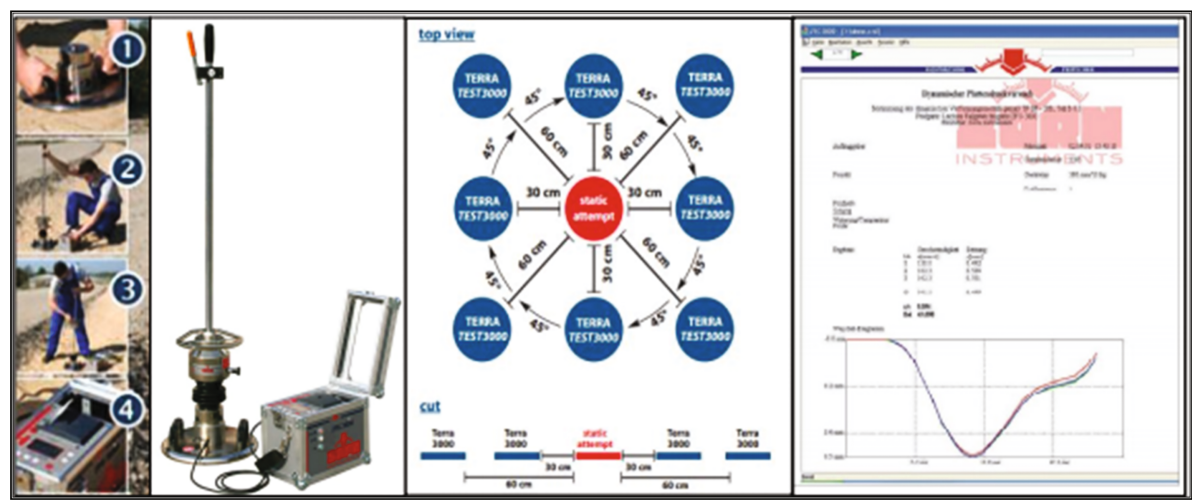

Fig. 1. Light Falling Weight Deflectometer (LFWD) (TIC Service Group 2013). 
accelerometer built in a steel case on the top of the plate. The drop weight, drop height and plate diameter are constants. The plate coefficient (c) and the Poisson's ratio $(\mu)$ are also set constant, therefore the dynamic subgrade modulus, $\left(\mathrm{E}_{\mathrm{vd}}\right)$ is calculated by a simplified Boussinesq equation (Zoltán 2008):

$$
\mathrm{E}_{\mathrm{vd}}=22.5 / \delta_{\mathrm{c}}
$$

To estimate dynamic modulus of deformation, $\mathrm{E}_{\mathrm{vd}}$ for each test in this study, eight position (nearly $45^{\circ}$ apart) surrounding the location of the static plate load test were selected and dynamic plate load test were performed. Each test was repeated three times, in each time three preconsolidation tests (pre-compaction to remove any bedding errors, and are ignored) were conducted as shown in Fig. 1.

\section{Static Plate Load Test (PLT)}

The Static Plate Load Test (PLT) has been a useful site investigation tool for many years and has been used for proof testing of pavement structure layers in many countries. Currently it is used for both rigid and flexible pavements. The test was conducted by the procedure recommended by ASTM D1196-93as shown in Fig. 2. The test consists of a circular plate (450 mm diameter) that is in close contact with the layer to be tested and measuring deflections under load increments. The load increments were applied via a hydraulic jack with a suitable load capacity. The load was applied in increments up to a final value of externally applied stress of $700 \mathrm{kPa}$. The corresponding settlement was monitored and recorded, by using three suitable dial gauges $\left(120^{\circ}\right.$ apart), for each increment until the settlement has ceased.

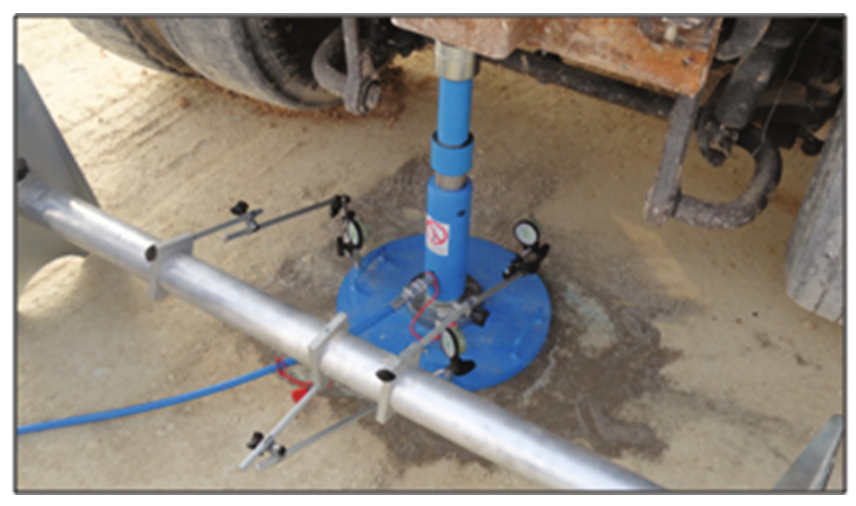

Fig. 2. Static Plate Load Test (PLT).

Plate loading tests can be used to estimate the modulus of subgrade reaction (k). Determination of the modulus of subgrade reaction is made in the field on the selected subgrade soil at its natural moisture content. This test is conducted by subjecting the 
subgrade to a known stress at a predetermined rate of speed using a loading system, and recording the resulting settlement. The modulus of subgrade reaction, $k$, can be calculated using the following relation (Yoder and Witczak 1975):

$$
k=p / \delta
$$

Where

$P=$ unit load on plate $(\mathrm{kN})$

$\delta=$ Settlement of the plate $(\mathrm{mm})$

The value of Young's modulus was obtained from the well-known relationship that correlates the young's modulus to the modulus of subgrade reaction (Bowels 1997):

$$
\mathrm{E}_{\mathrm{s}}=\mathrm{kB}\left(1-\mu^{2}\right)
$$

Where $\mathrm{B}$ in this case represents the diameter of the testing plate and $\mu$ is the Poisson's ratio and its value can be 0.5 for the assumption of flexible base plate (Yoder and Witczak 1975).

\section{Existing Relationships}

The Institute for Transport Sciences in Hungarian (KTI) launched a research program in 1995 aiming to convert the dynamic modulus obtained by that device $\left(\mathrm{E}_{\mathrm{vd}}\right)$ into the well-known static plate load test modulus $\left(\mathrm{E}_{2}\right)$ obtained by conventional measurements (research report, ÁKMI Kht 1995). After collecting 64 measurement results performed on different subgrade and subsoil materials, a general conversion formula was suggested as following:

$$
\mathrm{E}_{\mathrm{vd}}=0.52 \cdot \mathrm{E}_{2}+9.1
$$

Several correlation results between $\mathrm{E}_{2}$ and $\mathrm{E}_{\mathrm{vd}}$ are available in the international literature. The most relevant results are summarized in Fig. 3.

Figure 3 shows that the value of the static plate load test modulus clearly exceeds at least two times that of the $\mathrm{E}_{\mathrm{vd}}$ modulus. Some of the results show even higher ratios. Only two publications give a ratio less than two, but both of them are based on modulus values measured only at few points and within small intervals (Zoltán 2008).

Nazzal (2003) present a correlation study between the PLT and the LFWD on cement treated soils, lime treated soils, unstabilizsed fine-grained soils and granular soils. The relationship for modulus (surface modulus for LFWD) thus developed is as follows:

$$
\mathrm{E}_{\mathrm{PLT}}=-20.9+0.69\left(\mathrm{E}_{\mathrm{LFWD}}\right) \quad\left(\mathrm{R}^{2}=0.94, \text { for } 2.5 \mathrm{MPa}<\mathrm{E}_{\mathrm{LFWD}}<865 \mathrm{MPa}\right.
$$

These regression models are illustrated in Fig. 4. 


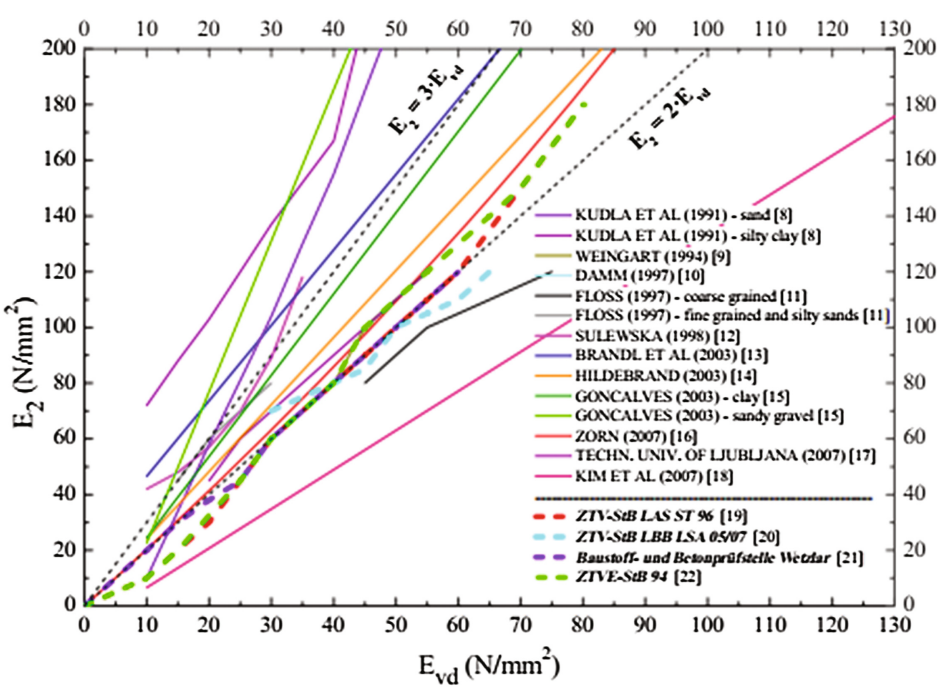

Fig. 3. Correlation results between $E_{2}$ and $E_{v d}$ (Zoltán 2008).

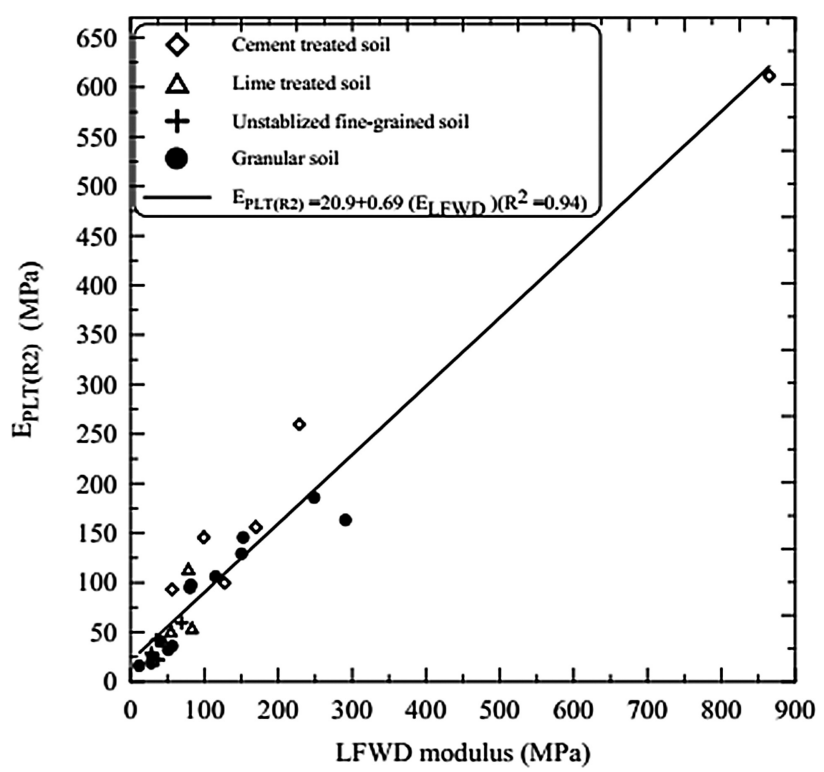

Fig. 4. Relationship between $\mathrm{E}_{\mathrm{PLT}(\mathrm{R} 2)}$ and $\mathrm{E}_{\mathrm{LFWD}}$ (Nazzal 2003). 


\section{Analysis of Results}

\subsection{Linear Regression Model}

In this study, collecting 40 measurement results for plate load test (PLT) performed on subgrade crushed limestone material in excess of $(38 \mathrm{~mm})$ in diameter by the field laboratory for civil engineering department at University of Anbar. After the division of project area as strips and establish the location of each point by mark, it has performed LFWD testing as shown in Fig. 5.

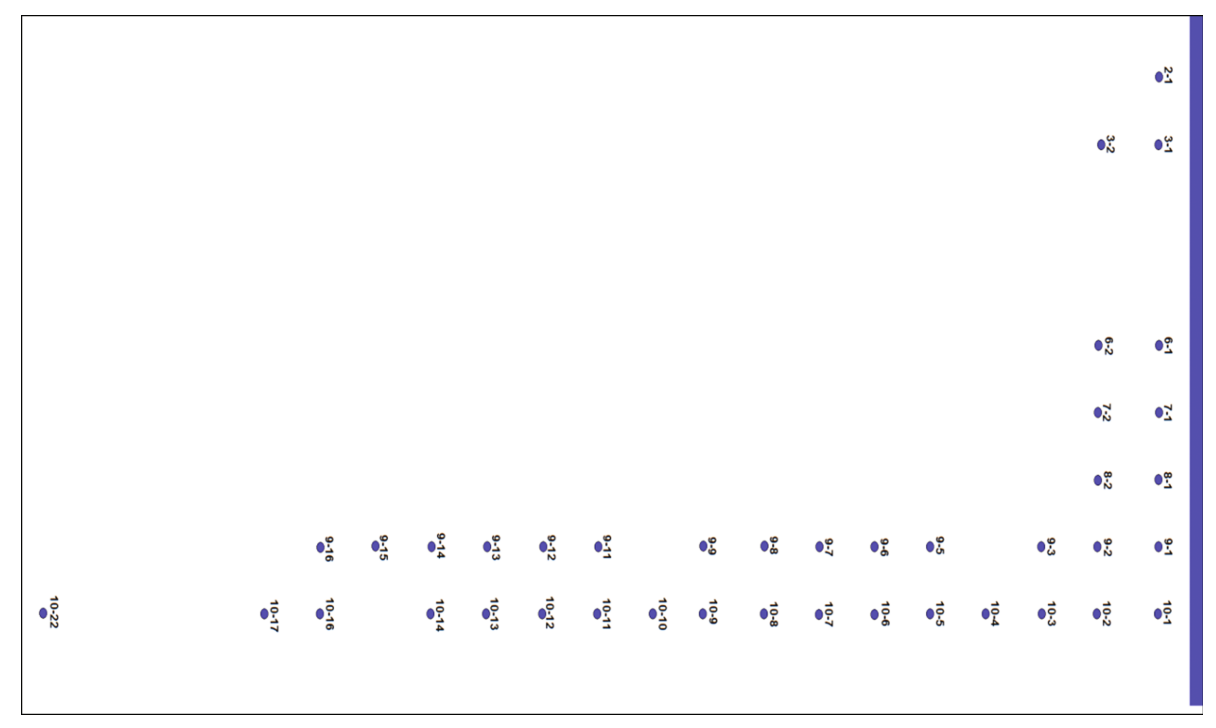

Fig. 5. Profile of the project area.

In order to characterize the variation of $E_{\mathrm{vd}}$ used as an independent value, descriptive statistics such as; minimum, maximum, mean, mode, median, variance, standard deviation, skewness and kurtosis etc. were calculated using the SPSS Version 20 (2012) package. Table 1 shows that the independent statistics value. Depending on the kind of soil and the degree of compaction, it can possible exceeding the limits of the lower and upper $\mathrm{E}_{\mathrm{vd}}$ values as (Nazzal 2003).

In this study, simple regression analysis was performed in the analysis. The relations between the measured $\mathrm{E}_{\mathrm{vd}}$, moduli values with conventional static $\mathrm{E}_{\mathrm{s}}$, moduli values were analyzed employing linear, power, logarithmic and exponential functions. Statistically significant and strong correlations were found to be linear.

The objective of this regression analysis is to determine the parameters in the least square error models, which is used to predict the $\mathrm{E}_{\mathrm{vd}}$ moduli from $\mathrm{E}_{\mathrm{s}}$ moduli, with their corresponding coefficient of determination, $\mathrm{R}^{2}$. In the linear regression models, the dependent variable is assumed to be a linear function of one or more independent 
Table 1. Descriptive statistics for $\mathrm{E}_{\mathrm{vd}}$ as an independent value.

\begin{tabular}{l|l}
\hline $\mathrm{N}$ & 40 \\
\hline Mean & 49.87 \\
\hline Std. error of mean & 4.7394 \\
\hline Median & 46.28 \\
\hline Mode & 27.61 \\
\hline Std. deviation & 29.97452 \\
\hline Variance & 898.472 \\
\hline Skewness & 3.957 \\
\hline Std. error of skewness & 0.374 \\
\hline Kurtosis & 20.714 \\
\hline Std. error of kurtosis & 0.733 \\
\hline Range & 187.7 \\
\hline Minimum & 21.3 \\
\hline Maximum & 209 \\
\hline Sum & 1994.91 \\
\hline
\end{tabular}

variables plus an error introduced to account for all other factors, a typical form of a regression linear model is as follow:

$$
\mathrm{Y}_{\mathrm{i}}=\beta_{o}+\beta_{1} x_{i 1}+\ldots \ldots \beta_{k} x_{i k}
$$

Where $\mathrm{Y}_{\mathrm{i}}$ is the dependent variable, and $x_{i 1}, \ldots, x_{i k}$ are the independent or explanatory variables, and $\beta_{o}$ is the disturbance or error term (SPSS Inc. 2009).

The coefficient of determination, $\mathrm{R}^{2}$, represents the proportion of variation in the dependant variable that is accounted by the regression model and has values from 0 to 1. If it is equal to one, the entire observed points lie on the suggested least square line, which means a perfect correlation exists. Significance level is the result of the statistic test with null hypothesis $\beta_{1}=0$; it is expressed in percent. The greater the significance level the more supportive the model to alternative hypothesis $\left(\beta_{1} \neq 0\right)$, which indicates that a relation does exist between the dependent and independent variable. Finally, the standard error is the square root of the mean square errors (MSE).

After collecting forty measurement results performed on subgrade layer, a general conversion formula was suggested as follows:

$$
\mathrm{E}_{\mathrm{vd}}=7.384+0.527 \mathrm{E}_{\mathrm{s}}
$$

This formula can be used to convert the measured $\mathrm{E}_{\mathrm{vd}}$ dynamic moduli values into conventional static $\mathrm{E}_{\mathrm{s}}$ moduli values. The coefficient of correlation gives a value of $\mathrm{R}^{2}=0.801$ and standard error $=13.56$ for 40 sites, which seems to be acceptable in geotechnical testing. This regression model is illustrated in Fig. 6. It can be seen that there are some values of $\mathrm{E}_{\mathrm{vd}}$ and $\mathrm{E}_{\mathrm{s}}$ outlier range caused by the low correlation coefficient $\left(\mathrm{R}^{2}\right)$. 


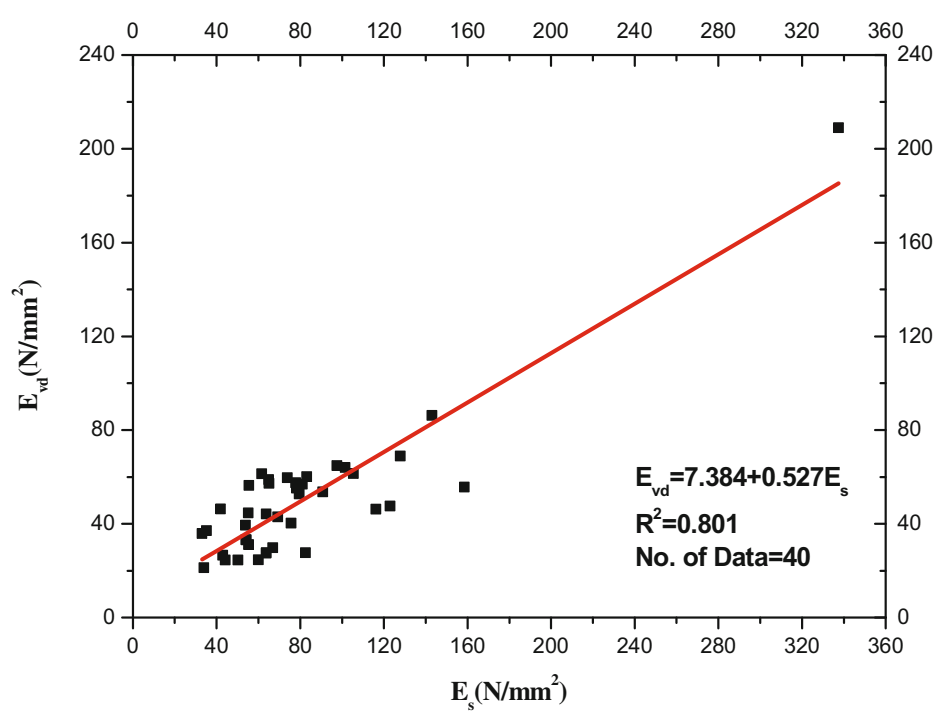

Fig. 6. Relationship between $\mathrm{E}_{\mathrm{vd}}$ and $\mathrm{E}_{\mathrm{s}}$.

\subsection{Multiple Regression Model}

In this study, 13 test results were selected from 40 sites. These sites have been tested by PLT and LFWD and have conducted field density test by sand cone method according to ASTM D1556-00. The modified proctor compaction test according to ASTM D1557-12 also showed that the maximum dry unit weight and the optimum moisture content for crushed limestone material in excess of $(38 \mathrm{~mm})$ in diameter were $17.6 \mathrm{kN} / \mathrm{m}^{3}$ and $5.6 \%$, respectively. Summary of results for this section is presented in Table 2.

Table 2. Summary of test results for crushed limestone layer.

\begin{tabular}{l|l|r|l|l|l}
\hline Strips & $\mathrm{E}_{\mathrm{vd}} \mathrm{MPa}$ & $\mathrm{E}_{\mathrm{s}} \mathrm{MPa}$ & $\mathrm{MC}$ (field) $\%$ & $\gamma_{\mathrm{dry}}$ (field) $\mathrm{kN} / \mathrm{m}^{3}$ & $\mathrm{D}_{\mathrm{pr}, \text { Modified }} \%$ \\
\hline $6-2$ & 37.08 & 35.21 & 7.59 & 16.99 & 96.56 \\
\hline $8-1$ & 59.63 & 73.93 & 13.57 & 17.27 & 98.12 \\
\hline $9-5$ & 21.3 & 34.01 & 16.2 & 16.25 & 92.36 \\
\hline $10-8$ & 44.2 & 63.84 & 14.08 & 16.54 & 93.96 \\
\hline $9-1$ & 68.8 & 127.90 & 15.6 & 16.42 & 93.30 \\
\hline $10-3$ & 24.53 & 50.30 & 15.7 & 16.23 & 92.20 \\
\hline $10-4$ & 46.33 & 41.91 & 13.08 & 16.72 & 94.99 \\
\hline $10-5$ & 26.55 & 43.05 & 13.8 & 16.13 & 91.64 \\
\hline $10-6$ & 52.63 & 79.56 & 14.08 & 16.89 & 95.95 \\
\hline $10-7$ & 47.53 & 123.00 & 13.8 & 16.74 & 95.12 \\
\hline $9-2$ & 64 & 101.57 & 16.11 & 16.22 & 92.18 \\
\hline $9-6$ & 24.6 & 59.97 & 15.32 & 16.23 & 92.21 \\
\hline $9-7$ & 86.2 & 143.12 & 16.2 & 16.92 & 96.14 \\
\hline
\end{tabular}


Multiple regression, a time-honored technique going back to Pearson's 1908 use of it, is employed to account for (predict) the variance in an interval dependent, based on linear combinations of interval, dichotomous, or dummy independent variables. The general purpose of multiple regression is to learn more about the relationship between several independent or predictor variables and a dependent or criterion variable. The typical form of the multiple regression model is as follow (SPSS Inc. 2009):

$$
y=b_{1} x_{1}+b_{2} x_{2}+\ldots .+b_{n} x_{n}+c
$$

Where $b_{1}, b_{2}, \ldots, b_{n}$ are the regression coefficients, representing the amount the dependent variable $y$ changes when the corresponding independent changes 1 unit. $c$ is a constant, where the regression line intercepts the $y$ axis, representing the amount the dependent $y$ will be when all the independent variables are 0 . The standardized versions of the $b$ coefficients are the beta weights, and the ratio of the beta coefficients is the ratio of the relative predictive power of the independent variables. The major conceptual limitation of all regression techniques is that one can only ascertain relationships, but never be sure about underlying causal mechanism (SPSS Inc. 2009).

Table 3. Model summaries of multiple regressions for prediction of $\mathrm{E}_{\mathrm{vd}}$.

\begin{tabular}{l|c|c|c|l}
\hline Independent variables & Coefficient & Std. error & t-Value & Sig. level \\
\hline Constant & -345.76 & 193.484 & -1.787 & 0.108 \\
\hline $\mathrm{E}_{\mathrm{s}}, \mathrm{MPa}$ & 0.375 & 0.1 & 3.733 & 0.005 \\
\hline $\mathrm{MC}, \%$ & 0.754 & 1.855 & 0.406 & 0.694 \\
\hline $\mathrm{D}_{\mathrm{pr}}, \%$ & 3.75 & 1.902 & 1.971 & 0.08 \\
\hline
\end{tabular}

Multiple regression analysis was carried out to correlate the measured $\mathrm{E}_{\mathrm{vd}}$ to three parameters, namely, static modulus $\left(\mathrm{E}_{\mathrm{s}}\right)$, moisture content $(\mathrm{MC})$ and degree of compaction $\left(\mathrm{D}_{\mathrm{pr}}\right)$ (Table 3$)$. Multiple regression model to predict $\mathrm{E}_{\mathrm{vd}}$ is given:

$$
\mathrm{E}_{\mathrm{vd}}=0.375\left(\mathrm{E}_{\mathrm{s}}\right)+0.754(\mathrm{MC} \%)+3.75\left(\mathrm{D}_{\mathrm{pr}} \%\right)-345.76
$$

The coefficient of correlation between the measured and predicted values is a good indicator to check the prediction performance of the model. Figure 7 shows the relationships between measured and predicted values obtained from the Multiple regression model for $\mathrm{E}_{\mathrm{vd}}$, which good correlation coefficient with $\mathrm{R}^{2}=0.804$.

\subsection{Target Values for Dynamic Models}

Direct conversion between dynamic, static models and degree of compaction is not frequently used in practice. Generally target values are given for different embankment and subgrade layers, more often depending on the required degree of compaction of the tested layer. $\mathrm{E}_{\mathrm{vd}}$ modulus target values are fixed in Germany, and some other countries. 


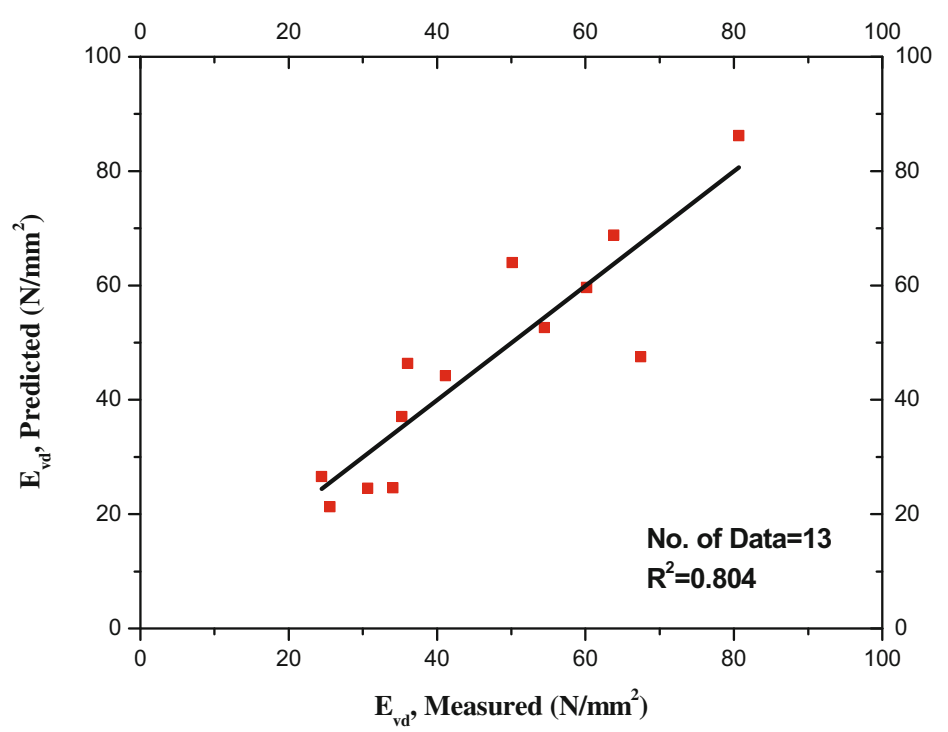

Fig. 7. Relationship of predicted and measured values of $E_{v d}$ for Multiple regression model.

Based on the results above, a table of target values can be introduced. Different $\mathrm{E}_{\mathrm{s}}$ and degree of compaction values are given for required $\mathrm{E}_{\mathrm{vd}}$ values in Table 4. It can be seen that $\mathrm{E}_{\mathrm{vd}}$ values reduce in access $10 \%$ compared with $\mathrm{E}_{\mathrm{s}}$ due to kind of soil layers and degree of compaction. Interpolation between given values is acceptable (Zoltán 2008).

Table 4. Target values for crushed limestone subgrade layers.

\begin{tabular}{l|l|l|l}
\hline \multirow{2}{*}{$\mathrm{E}_{\mathrm{s}} \mathrm{MPa}$} & $\mathrm{E}_{\mathrm{vd}} \mathrm{MPa}$ & $\mathrm{D}_{\mathrm{pr}} \%$ Modified & $\mathrm{E}_{\mathrm{s}} / \mathrm{E}_{\mathrm{vd}}$ ratio \\
\cline { 2 - 4 } & \multicolumn{2}{|c}{ Crushed limestone subgrade layers } \\
\hline 180 & 100 & $\geq 100$ & 2 \\
\hline 150 & 85 & $\geq 99$ & 2 \\
\hline 120 & 70 & $\geq 98$ & 2 \\
\hline 100 & 60 & $\geq 98$ & 2 \\
\hline 80 & 50 & $\geq 97$ & 2 \\
\hline 60 & 35 & $\geq 95$ & 2 \\
\hline 45 & 30 & $\geq 95$ & 2 \\
\hline 20 & 15 & $\geq 94$ & 1.5 \\
\hline
\end{tabular}

\subsection{Artificial Neural Network (ANN) Modeling of Overview}

When the materials are natural, there is always an uncertainty sourced from the nature of the materials. This could be the main reason why soft computing methodologies such as artificial neural networks, Fuzzy systems, genetic algorithms have been 
developed in recent years and adopted but used for some other application. These techniques attract more and more attention in several research fields because they tolerate a wide range of uncertainty (Jin and Jiang 1999). Multilayer feed-forward neural network model is the most widely used network for its efficient generalization capabilities. Figure 7 presents typical multi-layer feed-forward neural networks. This type of neural network consists of an input layer, one or more hidden layer(s) and an output layer. Layers are fully connected by arrows, and comprise a number of processing units, the so-called nodes or neurons. The strength of connections between neurons is represented by numerical values called weights. Each neuron has an activation value that is a function of the sum of inputs received from other neurons through the weighted connections (Demuth et al. 2006). The optimum number of hidden layers and the number of neurons in each hidden layer is problem specific. Therefore, trial and error should be carried out to choose an adequate number of hidden layers and the number of neurons in each hidden layer.

Back propagation is the most successful and widely used in neural network applications. In this method, the input is propagated from the input layer through the hidden layers to the output layer. The network input is connected to every neuron in the first hidden layer while each network output is connected to each neuron in the last hidden layer. In this case, this would call full connection ANN. The network weights were originally set to random values and new values of the network parameters (weights) are computed during the network training phase. The neurons output are calculated using (Abdul-Razzak and Yousif, 2007):

$$
O_{i}=F\left(\sum_{j} I_{j} \times W_{i j}+b_{i}\right)
$$

Where

$O i=$ the output of the neuron $\mathrm{i}, \mathrm{Ij}$ are the input of $\mathrm{j}$ neurons of the previous layer,

$W i j=$ the neuron weights, bi is the bias for the modeling, and

$F=$ the activation function.

The activation function is the portion of the neural network where all the computing is performed. The activation function maps the input domain (infinite) to an output domain (finite). The range to which most activation functions map their output is either in the interval $[0,1]$ or the interval $[-1,1]$. The most common activation functions belong to five families as follows: (1) linear activation function; (2) step activation function; (3) ramp activation function; (4) sigmoid activation function; and (5) Gaussian activation function. The network error is then back propagated from the output layer to the input layer in which the connection weights are adjusted. This process is repeated until the error is minimized to a preference level. The error incurred during the learning can be expressed as Mean Squared Error and is calculate using (Abdul Razzak and Yousif 2007):

$$
M S E=\frac{1}{n m} \sum_{\mathrm{i}=1}^{n} \sum_{\mathrm{j}=1}^{\mathrm{m}}\left(\mathrm{t}_{\mathrm{ij}}-\mathrm{y}_{\mathrm{ij}}\right)^{2}
$$

Where $\mathrm{t}$ is the target value, $\mathrm{y}$ is the output value. 


\subsection{ANN Model for Prediction of $\mathbf{E}_{\mathbf{v d}}$}

The use of ANN provides an alternative way to estimate dynamic modulus of deformation, $\mathrm{E}_{\mathrm{vd}}$. In this work a multi-layered feed-forward neural network with a back-propagation algorithm was adopted. (MATLAB 7.12005 ) software was used in neural network analyses having a three-layer feed-forward network (Alvarez and Babuska 1999). Forty cases of actual measured were extracted from experimental tests used in this study. The databases is randomly divided into three sets such as; training ( $70 \%$ of all data), test (15\% of all data), and verification (15\% of all data). The training set is used to adjust the connection weights, whereas the testing set is used to check the performance of the model at various stages of training and to determine when to stop training to avoid over-fitting. The validation set is used to estimate the performance of the trained network in the deployed environment (Shahin et al. 2008). A typical structure of artificial neural networks consists of many processing elements that are arranged in layers: an input layer, an output layer, and one or more layers in between, called intermediate or hidden layers (Fig. 8). Each processing element in a specific layer is interconnected to all the processing elements in the next layer via weighted connections. The scalar weights determine the strength of the connection between interconnected neurons. A zero weight refers to no connection between two neurons and a negative weight refers to a prohibitive relationship (Shahin et al. 2008). The model has one input parameter and one output parameter. The model has two hidden layers with nine nodes each (MATLAB software uses for determining the optimal number of hidden nodes rather than assuming a fixed number of hidden nodes in advance), and output layer with one node giving dynamic modulus of deformation, $\mathrm{E}_{\mathrm{vd}}$.

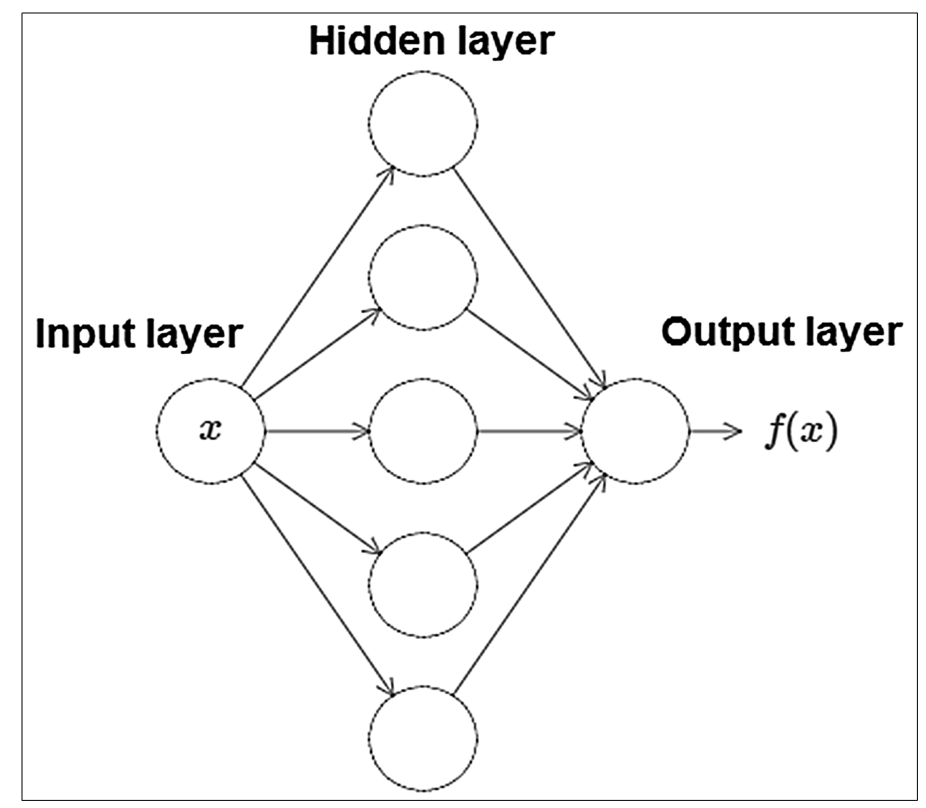

Fig. 8. Structure of Multi-layered feed-forward network (Michael 2015) 
By increasing the number of hidden neurons they can typically get a better approximation and do still better by further increasing the number of hidden neurons. In the analyses network of learning parameter, momentum parameters and networks training function, which is an activation (transfer) function for all layers, have typical values of 0.01, 0.9, trainLm (training Levenberg-Marquardt function) and tansig (transfer function) respectively. As in many other network training methods, models and parameters were used in order to reach the minimum Mean Square Error (MSE) values.

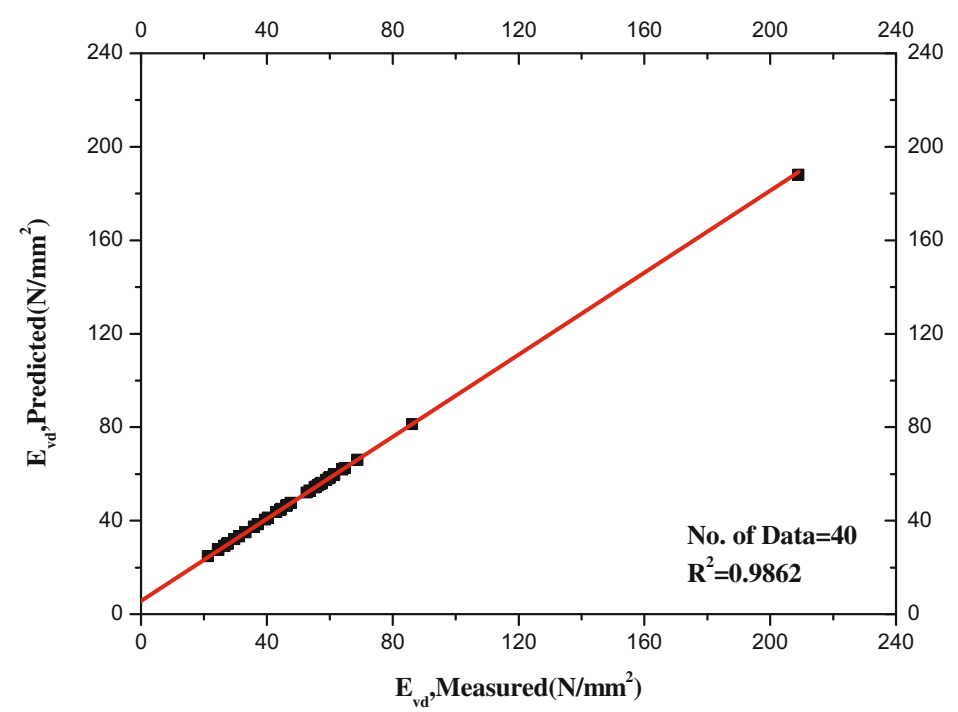

Fig. 9. Relationship of predicted and measured values of $E_{v d}$ for ANN Model.

In fact, the coefficient of determination between the measured and predicted $\mathrm{E}_{\mathrm{vd}}$ values is a good indicator to check the prediction performance of the model. Figure 9 shows the relationships between measured and predicted values obtained from the models for $\mathrm{E}_{\mathrm{vd}}$, with good coefficient of determinations. In this study, variance account for VAF (Eq. 12) and root mean square error (RMSE) (Eq. 13), indices were also calculated to control the performance of the prediction capacity of predictive models developed in the study as employed by (Alvarez and Babuska 1999):

$$
\begin{gathered}
V A F=\left[1-\frac{\operatorname{var}\left(y-y^{\prime}\right)}{\operatorname{var}(y)}\right] \times 100 \\
R M S E=\sqrt{\frac{1}{N} \sum_{i=1}^{N}\left(y-y^{\prime}\right)^{2}}
\end{gathered}
$$

Where $y$ and $y^{\prime}=$ the measured and predicted values, respectively.

If the VAF is 100 and RMSE is 0 , then the model will be excellent. The obtained values of VAF and RMSE given in Table 5 indicated a high prediction performance. 
Table 5. RMSE, VAF and $\mathrm{R}^{2}$ values used to predict $\mathrm{E}_{\mathrm{vd}}$.

\begin{tabular}{l|l|l|l|l}
\hline Model & Predictive model & RMSE & VAF\% & $\mathrm{R}^{2}$ \\
\hline LRM & $\mathrm{E}_{\mathrm{vd}}=7.384+0.527 \mathrm{E}_{\mathrm{s}}$ & 9.25 & 75.09 & 0.81 \\
\hline ANN & & 2.57 & 98.31 & 0.98 \\
\hline
\end{tabular}

\section{Conclusions}

The LFWD proved to be a truly light weight FWD and is highly transportable. It is very easy to operate and changes from the $10 \mathrm{~kg}$ to the $20 \mathrm{~kg}$ drop weights or loading plates (200 $\mathrm{mm}$ and $300 \mathrm{~mm}$ ) are quick and easy to do. All tests are saved automatically on a chip card, simply insert the card and the data can be transferred to the PC immediately. The basic information provided by the LFWD clearly proved to be very useful for construction quality control and assurance purposes.

The objective of this study is to evaluate the potential use of non-destructive testing device to measure the stiffness/strength parameters of highway materials and embankment soils during and after construction for landfill project. The field testing program included conducting tests using the investigated devices, in addition to standard tests, which included the static Plate Load Test (PLT), field density test by the sand cone method, and modified proctor compaction test). The field testing performed on subgrade crushed limestone material in excess of $(38 \mathrm{~mm})$ in diameter.

The results of the statistical analysis show that a good correlation do exist between the device under evaluation LFWD and the standard tests PLT, and degree compaction depending on standard tests. The relations obtained from statistical analysis, were linear regression to model and multiple regression for another. All regression models had an adjusted, correlation coefficient $\left(\mathrm{R}^{2}\right)$ greater than 0.8 .

A multi-layered feed-forward neural network with a back-propagation algorithm was used to demonstrate the feasibility of ANNs to predict the dynamic modulus of deformation, $\mathrm{E}_{\mathrm{vd}}$. Forty cases of actual field measurements were used for model development and verification. The predicted $\mathrm{E}_{\mathrm{vd}}$ obtained by utilising ANNs were compared with the measured $\mathrm{E}_{\mathrm{vd}}$. The results indicate that ANN model have the capability of predicting $\mathrm{E}_{\mathrm{vd}}$ with a high degree of accuracy. From VAF, RMSE indicators and correlation coefficient $\left(\mathrm{R}^{2}\right)$ results, it can be seen that the ANN model is more accurately than regression analysis to predict $\mathrm{E}_{\mathrm{vd}}$ as in Table 5 .

The result of this study suggests that LFWD can be reliably used to predict the modules obtained from PLT, and degree of compaction values, and hence can be used to evaluate the stiffness/strength parameters of subgrade layers.

The new dynamic target values could open up the opportunity to perform the quality control and assess the bearing strengths of the tested layer, not only by static plate load test, which proved to be time-consuming and labour intensive, but by dynamic devices too.

The widespread use of mentioned dynamic devices referred to above, may facilitate for contractors, laboratories and engineers in the highway and railway construction industry to perform quick and continuous quality control of embankments, subgrade and subsoil layers and backfills. 
Acknowledgment. The authors express his sincere thanks to the staff of the field laboratory for civil engineering department at University of Anbar for help in the conduct the field tests.

\section{References}

Zoltán, T.: Conversion between static and dynamic load bearing capacity moduli and introduction of dynamic target values. Periodica Polytech. Civil Eng. 52(2), 97-102 (2008)

Garcia, G., Thompson, M.R.: Subgrade strength/stiffness evaluation. University of Illinois, Dept of Civil and Environmental Engineering, Technical Note, 1215NCEL, MC-250, Urbana, IL 61801 (2004)

TIC Service Group: Test Equipment for Geotechnics and Pavements (2013). www. ticservicegroup.com.au

Yoder, E.J., Witczak, M.: Principles of Pavement Design. Wiley, New York (1975)

Bowels, J.E.: Foundation Analysis and Design, 5th edn. The McGraw-Hill Companies, New York (1997)

Institute for Transport Sciences: Measurement of load bearing capacity with lightweight deflectometers (Wemex/ ZFG). Research report, ÁKMI Kht (1995)

Nazzal, M.D.: Field evaluation of in-situ test technology for QC/QA during construction of pavement layers and embankments. M.Sc. thesis in civil engineering, Louisiana State University and Agricultural and Mechanical College (2003)

SPSS Inc.: PASW Statistics for Windows, Version 18.0. Chicago: SPSS Inc. (2009)

Jin, Y., Jiang, J.: Techniques in neural-network based fuzzy system identification and their application to control of complex systems. In: Leondes, C.T. (ed.) Fuzzy Theory Systems, pp. 112-128. Techniques and Applications, Academic Press, New York (1999)

Demuth, H.B., Beale, M., Hagan, M.: Neural network toolbox for use with matlab User's guide. MathWorks, Incorporated (2006)

Abdul-Razzak, A.A., Yousif, S.T.: Artificial neural network model for predicting nonlinear response of uniformly loaded fixed plates. Eng. Technol. 25(3), 334-348 (2007)

MATLAB 7.1 Software for technical computing and Model-Based Design. The MathWorks Inc. (2005)

Alvarez, G.M., Babuska, R.: Fuzzy model for the prediction of unconfined compressive strength of rock samples. Int. J. Rock Mech. Min. Sci. 36, 339-349 (1999)

Shahin, M.A., Jaksa, M.B., Maier, H.R.: State of the art of artificial neural networks in geotechnical engineering. Electron. J. Geotech. Eng. 8, 1-26 (2008)

Michael, N.: Neural Networks and deep learning. online book (2015) http:// neuralnetworksanddeeplearning.com/chap4.html 